\title{
FIELD VALIDATION OF ICESAT-2 DATA ALONG CHINARE ROUTE IN EAST ANTARCTICA
}

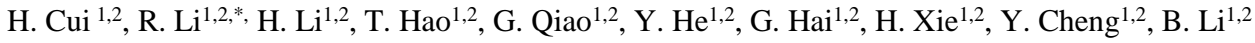 \\ ${ }^{1}$ Center for Spatial Information Science and Sustainable Development Applications, Tongji University, 1239 Siping Road, \\ Shanghai, China - (haotiancui, rli, lihw, tonghao, qiaogang, alenhe, ganghai, huanxie, chengyuan_1994, bofeng_li)@tongji.edu.cn \\ ${ }^{2}$ College of Surveying and Geo-Informatics, Tongji University, 1239 Siping Road, Shanghai, China
}

Commission III, WG III/9

KEY WORDS: Antarctica, ICESat-2, GNSS, Comparison in elevation.

\begin{abstract}
:
A field validation of the ICESat-2 elevation data has been conducted along the CHINARE (CHINese Antarctic Research Expedition) route near the Amery Ice Shelf in East Antarctica from December 2019 to February 2020. The study area covers a $520 \mathrm{~km}$ traverse from the coastal Zhongshan Station to the inland Taishan Station. We deployed two roof-mounted GNSS receivers to collect elevation data along the traverse and reduced them to the ice surface height with measured boresight parameters. The comparison of the ICESat2 data (Release 003) with the high-precision ground-based GNSS along the traverse shows that the elevations of ATL06 ice surface products are accurate to $1.5 \mathrm{~cm}$ with $9.1 \mathrm{~cm}$ precision, and the elevations of ATL03 photon events are accurate to $4.3 \mathrm{~cm}$ with $8.5 \mathrm{~cm}$ precision. The validation results indicated high accuracy of $1.5-4.3 \mathrm{~cm}$ of ICESat-2 data, which provides the potentials to observe and evaluate the low-level mass changes in East Antarctica. The methodology and hardware system can be improved to execute a continuous assessment of ICESat-2 data in the following mission period.
\end{abstract}

\section{INTRODUCTION}

Since the successful launch on September 15, 2018, NASA's Ice, Cloud, and Land Elevation Satellite-2 (ICESat-2) has acquired and delivered surface elevation data from $\sim 88^{\circ} \mathrm{N}$ to $\sim 88^{\circ} \mathrm{S}$ to the public (Markus et al., 2017; Smith et al., 2019). With the Advanced Topographic Laser Altimetry System (ATLAS), these unique altimetry data have been acquired in photon-counting mode to provide centimeter-level observing accuracy for monitoring cryospheric surface changes. One of the scientific goals of the satellite is to determine ice sheet mass balance and reduce the uncertainty of the estimated sea level rise contribution from Antarctica (Neumann et al., 2019). More Specifically, the primary requirement of accuracy for quantifying ice sheet surface change is better than $0.4 \mathrm{~cm} \mathrm{a}^{-1}$ (Markus et al., 2017). As a followup satellite to the previous ICESat laser altimetry mission (Zwally et al., 2002), ICESat-2 utilizes 6 altimeter beams and measures the Antarctic surface along 1387 unique orbits with a rigorous repeat cycle of 91 days. ATLAS observation mode is configured into 3 beam pairs spaced by $\sim 3.3 \mathrm{~km}$ apart from the center pair with a distance of $90 \mathrm{~m}$ between strong and weak beams. The beam pattern (three weak-strong pairs) makes it also capable of acquiring local slopes quantitatively in polar regions (Markus et al., 2017).

Validation campaigns are important for satellite altimetry missions, especially for ICESat-2 which adopts a new technique of photon-counting. Prior to the study of ICESat-2 assessments, calibration and validation have been carried out several times for the pioneers including ICESat and Multiple Altimeter Beam Experimental Lidar (MABEL). Fricker et al. (2005) used a GPSderived digital elevation model of the salar de Uyuni, Bolivia (an ideal cal/val site with an albedo similar to that of ice sheets) for the confirmation of the accuracy of ICESat. Similarly, Magruder et al. (2005) carried out verification for ICESat laser altimeter using a passive array of corner cube retro reflectors (CCR) which were implemented at White Sands Space Harbor (WSSH). Hofton et al. (2013) documented the relative biases of -3.6 to + $14.7 \mathrm{~cm}$ and precisions of $0.8-5.5 \mathrm{~cm}$ between ICESat data and the airborne laser altimeter along a $350-\mathrm{km}$ traverse of $86^{\circ} \mathrm{S}$. Siegfried et al. (2011) compared four passes of ICESat track 0412 (campaigns L3I, L3J, L2D, and L2E) using repeat GPS measurements over the Greenland Ice Sheet and documented a campaign-dependent elevation bias ranging from $-0.112 \pm 0.030$ $\mathrm{m}$ (L3J) to $0.121 \pm 0.071 \mathrm{~m}$ (L2E) which is large enough to have an influence on mass-balance assessments. Kohler et al. (2013) validated the ICESat data utilizing the cross-over analysis with ground-based GPS along the 2007-09 Norway-USA traverse over Antarctic Ice Sheet (AIS) and showed the accuracy ranging from -12 to $-2 \mathrm{~cm}$ with a precision of $15.8 \mathrm{~cm}(1 \sigma)$ between $\mathrm{dh} / \mathrm{dt}-$ corrected ICESat data and GPS-derived surface elevations. Schröder et al. (2017) also conducted a traverse-validated campaign for ICESat data between Vostok Station and the East Antarctic coast and demonstrated a decimetre level accuracy over a wide extent of varying surface slopes. Borsa et al. (2019) assessed the ICESat data of the entire mission at the salar de Uvuni, Bolivia using a DEM extracted from geodetic surveys and report an overall surface measurement bias and precision of 0.0 $\pm 4.0 \mathrm{~cm}$. In addition to the above-mentioned studies, several validations have been conducted for MABEL data which are used to simulate key aspects of the ICESat-2 measurements (Magruder et al., 2018; Brunt et al., 2014 and 2017). Brunt et al. (2017) show that the surface-elevation biases and assessments of measurement precisions for MABEL data are less than $0.12 \mathrm{~m} \pm 0.09 \mathrm{~m}$ over the Greenland Ice Sheet interior. Magruder et al. (2018) report the meter-scale elevation bias and the $13-24 \mathrm{~cm}$ precision between the collected MABEL data and a DEM derived from a ground-based GPS survey over Greenland. These analyses not only provided assessments of previous altimeters performance

Corresponding author 
but also contributed to the strategies in support of cal/val of ICESat-2 satellite mission.

For the validation of ICESat-2 satellite, the mission team firstly conducted a $750 \mathrm{~km}$ ground-based kinematic GPS traverse along $88^{\circ} \mathrm{S}$ which intersects $20 \%$ of the ICESat- 2 orbits from December 2017 to January 2018 and presented an overview of the groundbased GPS data quality over the relatively flat interior of the Antarctic ice sheet (Brunt et al., 2019a). Thereafter, they continued to measure the $88^{\circ} \mathrm{S}$ traverse during December 31 , 2018, and January 11, 2019, and compared the ICESat-2 data products (Release 001) using kinematic Global Navigation Satellite Systems (GNSS) observations (Brunt et al., 2019b). Their results indicate that the photon elevations of ATL03 are accurate to $5 \mathrm{~cm}$ with a precision of $13 \mathrm{~cm}$, while that of ATL06 elevation points are accurate to $3 \mathrm{~cm}$ with a precision of $9 \mathrm{~cm}$. Moreover, Brunt et al. (2021) assessed ICESat-2 related products using three separate $88 \mathrm{~S}$ traverses and documented that the bias of ICESat- 2 elevation is better than $\pm 3.3 \mathrm{~cm}$ and the precision is better than $\pm 7.2 \mathrm{~cm}$. Additionally, the team utilized corner cube retroreflectors (CCRs) installed in a specific pattern along satellite ground tracks. Results of the comparison from known positions of the CCRs on the surface and the returned signatures show that the horizontal locations are accurate to $3.5 \mathrm{~m}$ with a standard deviation of $1.6 \mathrm{~cm}$; additionally, the averaged footprint diameter is $10.9 \mathrm{~m} \pm 2.1 \mathrm{~m}$ (Magruder et al., 2020a, 2020b). The geolocation error of point control performance is up to $4.4 \pm 6.0$ $\mathrm{m}$ with a range from $2.5 \mathrm{~m}$ for beam 6 to $4.4 \mathrm{~m}$ for beam 2 after the on-orbit calibration (Luthcke et al., 2021).

In this paper, we designed and conducted a field observation along the $36^{\text {th }}$ CHINARE (CHINese Antarctic Research Expedition) route during December 2019 and February 2020 from Zhongshan Station to Taishan Station, which is a part of the $\sim 1250 \mathrm{~km}$ long-term observation traverse from Zhongshan Station to Dome A (Ding et al., 2011; Cui et al., 2020). Ding et al. (2011) report the variety of surface slopes along the traverse: an average slope of $11 \mathrm{~m} \mathrm{~km}^{-1}$ from $68 \mathrm{~km}$ to $202 \mathrm{~km}, 5.4 \mathrm{~m} \mathrm{~km}$ ${ }^{1}(202-524 \mathrm{~km}), 5.0 \mathrm{~m} \mathrm{~km}^{-1}(524-800 \mathrm{~km}), 4.3 \mathrm{~m} \mathrm{~km}^{-1}$ (ice-divide area spanning $800-1128 \mathrm{~km}$ ), and $\sim 2.6 \mathrm{~m} \mathrm{~km}^{-1}$ (Dome area spanning 1128-1248 km). We compare the collected groundbased GNSS data with the intersected ICESat- 2 data along the first $520 \mathrm{~km}$ of the traverse located at the steeper regions and present validations of the Release 003 of the ICESat-2 geolocated photon elevation (ATL03) and land ice surface elevation products (ATL06), providing an assessment of the ICESat-2 performance over the diverse slope areas.

\section{DATA}

\subsection{ICESat-2 Data}

We obtained the ICESat-2 L2A Global Geolocated Photon Data (ATL03) and L3A Land Ice Height data (ATL06) through the National Snow and Ice Data Center along the 60 ascending and 78 descending tracks over AIS between November 10, 2019, and February 21, 2020. The heights of ATL06 and ATL03 products are referenced to the ITRF 2014 frame, and the geolocation is referenced to the WGS84 ellipsoid. As the primary input for higher-level data products, ATL03 photon events are comprised of geolocation (latitude, longitude, and ellipsoidal height) and surface-reflected signal confidence. The resolution of the ATL03 product is $0.7 \mathrm{~m}$ as well as the interval of the footprints of ATLAS in the along-track direction (Neumann et al., 2019). ATL06 product is the fitted geolocation information from photons assembled in the $40 \mathrm{~m}$ along-track segments, posting at the interval of $20 \mathrm{~m}$ along the track. (Smith et al., 2019). For our analyses, we evaluate ICESat-2 laser beams grouped by ground tracks (GT1L, GT1R, GT2L, GT2R, GT3L, GT3R), individually. Taking the time of spacecraft reorientation (28-Dec-2018, 07Sep-2019) into consideration, we disposed the comparison on instrument spots (1 through 6). During our study period, the correspondence is (Laser spot 1: 3R), (Laser spot: 3L), (Laser spot 3: 2R), (Laser spot 4: 2L), (Laser spot 5: 1R), and (Laser spot 6: 1L) (Neumann et al., 2019).

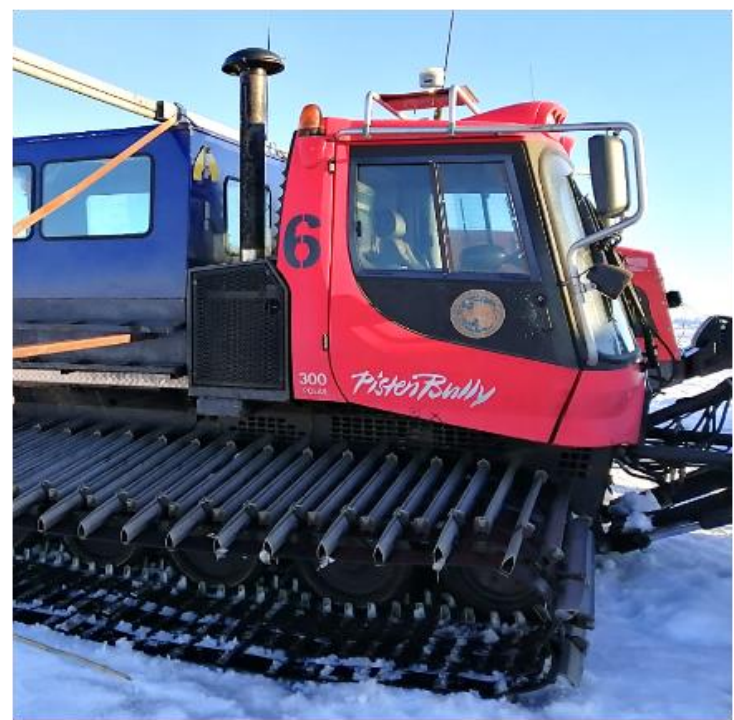

Figure 1. GNSS roving receivers mounted on the roof of a Pisten Bully snowcat and for ice surface elevation estimation from the GNSS observations.

\subsection{GNSS Data}

We collected GNSS data with a total of $\sim 1008 \mathrm{~km}(\sim 516 \mathrm{~km}$ inbound during December 10-15, 2019 and $\sim 492 \mathrm{~km}$ outbound during February $8-3,2020$ ) along the $36^{\text {th }}$ CHINARE inland expedition from Zhongshan Station to Taishan Station, utilizing two roving GNSS receivers mounted on the roof of the snowcat (Fig 1). The data used for comparison are the combination of two receivers because of incidental battery problems and interequipment interferences. The GNSS receivers recorded data from the Global Positioning System (GPS), Global Navigation Satellite System (GLONASS), Galileo Global Navigation Satellite System (Galileo), and BeiDou Navigation Satellite System (BDS). We implemented five GNSS base stations on the ice surface along the traverse before the beginning of the next $100 \sim \mathrm{km}$ survey of the snowcat, which is used to provide precise position information. We set the sampling rate to $1 \mathrm{~Hz}(\sim 4 \mathrm{~m}$ ground resolution) and elevation mask angle to $7^{\circ}$ to cut down the multipath effect.

\section{METHODS}

\subsection{GNSS Data Processing and Assessing}

The collected GNSS data of the base stations along the traverse were processed primarily using the precise point positioning (PPP) technique embedded in the software of multi-frequency and multi-system instantaneous PPP (MUSIP) developed at Tongji University ( $\mathrm{Li}$ et al., 2019). Two roving receivers mounted on the snowcat were dealt with using the post-processed kinematic (PPK) positioning technique implemented in an opensource software package RTKLIB version 2.4 .3 (http://www.rtklib.com) developed by the Laboratory of Satellite Navigation at Tokyo University of Marine Science and Technology (Takasu et al., 2009). We estimated the snowcat 
positions during a journey of $\sim 100 \mathrm{~km}$ from each base station. Moreover, we utilized the processed GNSS data at each intersection that occurred during observations, camping breaks, and instrument installations to assess the accuracy and precision (Kohler et al., 2013).

\subsection{Extraction of Ice Surface Elevation from GNSS observation}

The elevation of ice surface relative to the antenna phase-center mounted on the snowcat is determined as:

$$
H_{\text {Ice surface }}=H_{G N S S}-h_{0}-h_{1}-h_{2}
$$

where $h_{0}$ is the antenna phase-center height above the mounting plane (given by the manufacturer as $10.1 \mathrm{~cm}$ ) and $h_{1}$ is the vertical distance between the plane and a reference point on the snowcat marked by a black arrow (measured by the SOKKIA $\mathrm{CX}-102 \mathrm{LN}$ total station three times and estimated as an average of $191.1 \mathrm{~cm}) . h_{2}$ is the distance from the black arrow to the ice surface that we measured along the traverse with steel tape during breaks. To mitigate the uncertainty, we measured the distance three times with an interval of $10 \mathrm{~cm}$. There were 20 locations we measured along the traverse where three were mistakenly measured to the bottom of the indentation of tracks. For other traverse points away from these direct ice surface measurements, we interpolated the values of $h_{2}$ using interpl function from MATLAB with parameters 'linear' and 'extra' along the whole route. Linear interpolation was based on the accumulative distance starting from Zhongshan Station. The value at an unknown point is interpolated from the two closest $h_{2}$ direct measurements linearly using the inverse distance as a weight (IDW). Moreover, we extrapolated the values for points that are beyond the first and last $h_{2}$ measurements. Thus, the elevation of ice surface can be computed from $H_{G N S S}$ to $H_{\text {Ice surface }}$ with these three parameters in Equation (1).

\subsection{Computation of GNSS - ICESat-2 Crossovers Location}

The new ICESat-2 mission data provided three pairs of ground tracks (weak and strong in one pair) which are $3.3 \mathrm{~km}$ apart. Owing to the orbital inclination of $92^{\circ}$, ICESat-2 data are converged near $88^{\circ} \mathrm{S}$ in Southern Hemisphere (Markus et al., 2017). The spacing of ground tracks increases from inland to coast and therefore the number of data becomes sparser. In this study, we selected ICESat-2 products from Zhongshan Station $\left(\sim 69.37^{\circ} \mathrm{S}\right)$ to Taishan Station $\left(\sim 73.85^{\circ} \mathrm{S}\right)$ and added the range of 30 days spanning the GNSS-collected window to acquire adequate data for statistics and reduce the influences caused by the variation of weather. Based on the on-orbit pointing control of the nominal location ( $45 \mathrm{~m}$; Markus et al., 2017), we set buffers of $50 \mathrm{~m}$ to cover all available nominal tracks that are intersected with the trajectories of the snowcat.

After that, we searched for the spatial location of all crossover points referred to GNSS data points and raw ICESat-2 data. To simplify the processing of crossovers location, we first generalized the trajectories of snowcat using the Generalization Toolset embedded in ArcGIS Pro as the primary input to compute the crossover locations. The crossovers are defined by GNSS trajectories and ICESat-2 ascending and descending tracks depicted as Fig. 2. The exact location of a crossover can then be obtained by solving the following equation set:

$$
\left\{\begin{array}{l}
(\mathrm{x} 2-\mathrm{x} 1) * \mathrm{~d} 1=\mathrm{x} 0-\mathrm{x} 1 \\
(\mathrm{x} 4-\mathrm{x} 3) * \mathrm{~d} 2=\mathrm{x} 0-\mathrm{x} 3 \\
(\mathrm{y} 2-\mathrm{y} 1) * \mathrm{~d} 1=\mathrm{y} 0-\mathrm{y} 1 \\
(\mathrm{y} 4-\mathrm{y} 3) * \mathrm{~d} 2=\mathrm{y} 0-\mathrm{y} 3
\end{array}\right.
$$

where $\mathrm{d} 1$ is the distance from the starting point of segment A1A2 $(\mathrm{x} 1, \mathrm{y} 1->\mathrm{x} 2, \mathrm{y} 2)$ to the intersection point relative to the length of $\mathrm{A} 1 \mathrm{~A} 2$ and $\mathrm{d} 2$ is the distance from the starting point of B1B2 $(\mathrm{x} 3, \mathrm{y} 3->\mathrm{x} 4, \mathrm{y} 4)$ to the intersection point relative to the length of B1B2. When four solutions are figured out and $0 \leqslant \mathrm{~d} 1<1,0 \leqslant$ $\mathrm{d} 2<1$, then the two segments intersect and the position of the crossover is (x0, y0; Greene et al., 2017). It is emphasized that there may be more than one intersection that occurred along the GNSS trajectories. We recognized and recorded them by each crossover separately.

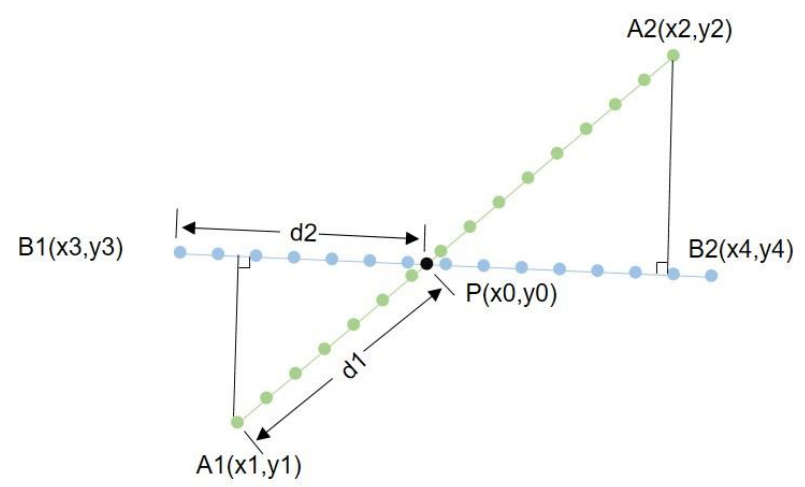

Figure 2. Diagram of crossover calculation for two assumed lines.

Furthermore, we selected ice surface points (ATL06) and photons (ATL03) at each crossover using different window sizes ( $\sim 80 \mathrm{~m}$ for ATL06 and $\sim 40 \mathrm{~m}$ for ATL03) to achieve a more efficient comparison between GNSS data and ICESat-2 data.

\subsection{Comparison of GNSS and ICESat-2}

Once the ATL06 and ATL03 data were selected at each crossover location, we filtered ATL06 data with the flag atl06_quality_summary value of 0 to reduce the impact of nonsignal and noisy measurement. For each retained ATL06 ice surface point, a 20-m radius window was applied to search for the adjacent GNSS points (Fig. 3). We then computed the difference between the ATL06 points and the median of at least five eligible GNSS readings. The median of all the ATL06GNSS height differences is regarded as the bias, together with the $1 \sigma$ standard deviation as the surface measurement precision. Similarly, we extracted ATL03 photons which are filtered by a confidence flag signal_conf_ph equal to 1 (buffer), 2 (low), 3 (medium), 4 (high). For every signal photon in the ATL03 subset, a 4 m-wide search window was used to track the nearest GNSS point and form a pair to calculate their elevation difference depicted in Fig. 2. If the number of pairs exceeds 30, we use the median among them to be the representative ATL03-GNSS height difference between the ATL03 and GNSS data at this intersection.

Considering the discrepancies of $h_{2}$ values, we compared the ICESat-2-GNSS crossover points in two ways. Firstly, we compared ICESat-2 elevations with the GNSS surface height at each snow-surface measurement point in a $5-\mathrm{km}$ radius restricted zone to obtain more accurate ground elevation verification results. Secondly, we compared them along the entire traverse route without constraints. It should be emphasized that, in order to lessen unexpected errors caused by similar noise photons being 
wrongly identified as signal photons, the comparison results with a difference of more than $2 \mathrm{~m}$ were excluded.

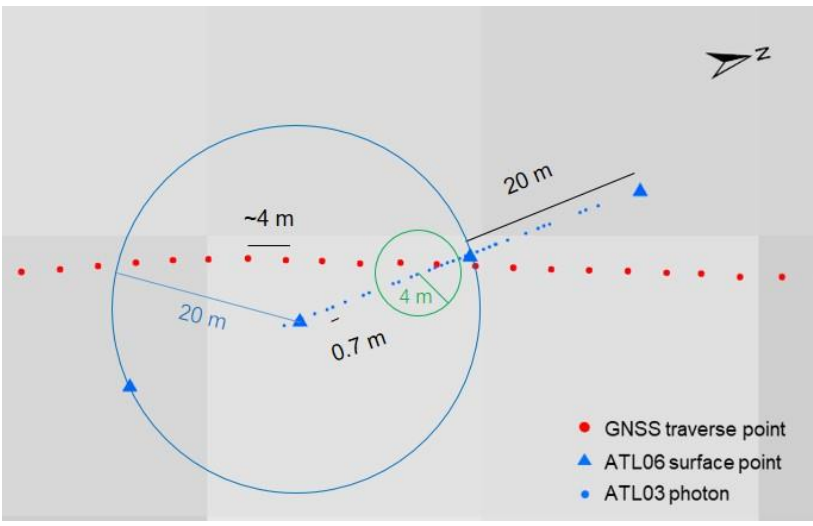

Figure 3. ATL06 ice surface points, ATL03 photons, and GNSS traverse points. $20 \mathrm{~m}$ is the searching radius (blue circle) for ATL06 points and $4 \mathrm{~m}$ is the searching radius (green circle) for ATL03 photons.

\section{RESULTS}

\subsection{GNSS Data Assessment}

The elevation precision values given by the GNSS PPP processing software are at the sub-centimeter level. For the roving GNSS receivers, a threshold of the precision given by the GNSS PPK positioning software was utilized to filter out large errors originated from rough terrain features and other noises. We assembled a sum of 625,358 GNSS traverse points with an average internal elevation accuracy of $1.6 \pm 0.6 \mathrm{~cm}$ given by the software system. A crossover analysis of 26 crossover points showed that the elevation accuracy of the GNSS traverse is $0.3 \pm$ $5.8 \mathrm{~cm}$.

\subsection{Validation of ICESat-2 Data along the GNSS Traverse}

During the mission period, we measured $h_{2}$ at 17 reliable locations. The average of the measured $h_{2}$ is $94.0 \mathrm{~cm}$ with a standard deviation of $2.8 \mathrm{~cm}$. This variation is related to the microtopography and firn density changes at different locations along the traverse. Out of the 134 intersections between the GNSS traverse and ICESat-2 tracks, we selected 60 intersections that were adjacent to $h_{2}$ direct measurement locations in a $5 \mathrm{~km}$ buffer to acquire a more realistic comparison. The average distance between the $h_{2}$ measured locations and GNSS-ICESat2 intersections is $\sim 2366 \mathrm{~m}$. We validated the elevations of ATL06 ice surface points and ATL03 photons using the GNSS-surveyed elevations and calculated the bias and precision of the height differences according to six types of ICESat-2 ground tracks. Positive bias values indicated that the ICESat- 2 surface was above the GNSS-surveyed surface. The comparison results were computed along inbound and outbound traverses, respectively. The number of inbound traverse results is 370 for ATL06 and 11997 for ATL03. There are also 251 and 6052 for outbound traverse results in both products. Along the inbound traverse, each GNSS base station (Base 1-5 with an interval of $\sim 100 \mathrm{~km}$ ) was deployed on the ice surface and kept working during the batteries' lifetime ( $\sim 3$ days). However, we had to use Base 1 implemented near the Russian Progress Station during the outbound traverse since the other four base stations were out of power. Data points exceeding the $2 \mathrm{~m}$ filtering threshold for ATL06-GNSS and ATL03-GNSS were eliminated which were attributed to time gaps or noises from these two datasets (Brunt et al., 2019b).

Within the $5 \mathrm{~km}$ constraint of direct $h_{2}$ value, we present our ATL06 assessment results as Bias \pm Precision (number of points): Spot 6 is $+2.7 \pm 9.6(\mathrm{~N}=64)$, Spot 5 is $+3.0 \pm 7.3(\mathrm{~N}=62)$, Spot 4 is $+0.7 \pm 7.9(\mathrm{~N}=48)$, Spot 3 is $-2.3 \pm 12.0(\mathrm{~N}=42)$, Spot 2 is +1.3 $\pm 8.4(\mathrm{~N}=33)$, Spot 1 is $-0.7 \pm 8.7(\mathrm{~N}=36)$. Compared to the processed GNSS elevation observation, the median difference of ATL06 land ice surface points range from $-2.3 \mathrm{~cm}$ to $3.0 \mathrm{~cm}$ and the precision $(1 \sigma)$ ranges from $7.3 \mathrm{~cm}$ to $12.0 \mathrm{~cm}$ for the six ICESat-2 tracks. Similarly, the ATL03 assessment results are: Spot 6 is $+5.9 \pm 5.9(\mathrm{~N}=1518)$, Spot 5 is $+1.7 \pm 6.7(\mathrm{~N}=2608)$, Spot 4 is $-0.5 \pm 6.7(\mathrm{~N}=862)$, Spot 3 is $+5.8 \pm 14.0(\mathrm{~N}=1356)$, Spot 2 is $+4.2 \pm 7.7(\mathrm{~N}=800)$, Spot 1 is $+4.6 \pm 10.9(\mathrm{~N}=2695)$. The bias of ATL03 photons ranges from $-0.5 \mathrm{~cm}$ to $5.9 \mathrm{~cm}$ and the precision ranges from $5.9 \mathrm{~cm}$ to $14.0 \mathrm{~cm}$.

We further extended the comparison between ICESat-2 tracks and GNSS traverse to all intersections without the $5 \mathrm{~km}$ constraint. The ATL06 assessment results show as Bias \pm Precision (number of points): Spot 6 is $+2.9 \pm 12.0(\mathrm{~N}=111)$, Spot 5 is $+2.5 \pm 12.7(\mathrm{~N}=116)$, Spot 4 is $-0.3 \pm 12.4(\mathrm{~N}=101)$, Spot 3 is $-2.8 \pm 12.4(\mathrm{~N}=106)$, Spot 2 is $-1.1 \pm 12.6(\mathrm{~N}=88)$, Spot 1 is $2.6 \pm 13.0(\mathrm{~N}=99)$. Likewise, we present the ATL03 results as: Spot 6 is $+6.4 \pm 12.6(\mathrm{~N}=2055)$, Spot 5 is $+4.5 \pm 12.5(\mathrm{~N}=4542)$, Spot 4 is $+0.2 \pm 7.3(\mathrm{~N}=1245)$, Spot 3 is $+0.5 \pm 11.8(\mathrm{~N}=4272)$, Spot 2 is $+2.8 \pm 10.6(\mathrm{~N}=1233)$, Spot 1 is $+1.7 \pm 12.1(\mathrm{~N}=4490)$. The ATL06 and ATL03 data present an overall bias of $0.5 \mathrm{~cm}$ and $3.7 \mathrm{~cm}$, respectively, which are comparable to the above results (ATL06: $1.5 \mathrm{~cm}$; ATL03: $4.3 \mathrm{~cm}$ ). However, the overall precision values of $12.7 \mathrm{~cm}$ (ATL06) and $11.5 \mathrm{~cm}$ (ATL03) are a little larger than $9.1 \mathrm{~cm}$ (ATL06) and $8.5 \mathrm{~cm}$ (ATL03). The discrepancy may attribute to the fluctuation in the procedure of GNSS surface-height reduction using the interpolation of $h_{2}$ value.

In addition, we further examined the performance of weak (Spot 6,4,2) and strong (Spot 5,3,1) beams. Although there are no significant elevation differences between the GNSS data and ICESat-2 observations, the number of ATL03 photons accepted for the assessment is different. In total, the sum of photons of weak and strong beams is 3180 and 6659 for 5 km-results, respectively, and 4533 and 13304 without constraint, respectively. This ratio of weak to strong beam photons of up to $\sim 1: 3$ is lower than the reported transmitter beam energy ratio of 1:4 (Markus et al., 2017). This should be attributed to the data quality screening during the mission team's data production procedure as well as our data filtering and GNSS point pairing processes.

\section{CONCLUSIONS}

In this paper, we utilized a field observation system to validate the ICESat- 2 ice surface elevations along the $36^{\text {th }}$ CHINARE route over East Antarctica Ice Sheet. The primary results show that the elevation accuracy of the ATL06 ice surface points is accurate to $1.5 \mathrm{~cm}$ with a precision of $9.1 \mathrm{~cm}$; The elevation accuracy of the ATL03 photons is $4.3 \mathrm{~cm}$ with a precision of 8.5 $\mathrm{cm}$. Although we have presented short period validation results for ICESat-2 data, it is meaningful to monitor the performance of ATLAS in a longer time. Therefore, we will improve our methodology to potentially perform more such assessments during the following mission period. 


\section{ACKNOWLEDGEMENTS}

The logistic and technical support provided by the 36th CHINARE team and the Polar Research Institute of China is appreciated. This study was supported by the National Science Foundation of China (41730102) and the Polar Expedition Office of the State Oceanic Administration.

\section{REFERENCES}

Borsa, A.A., Fricker, H.A., Brunt, K.M., 2019. A Terrestrial Validation of ICESat Elevation Measurements and Implications for Global Reanalyses. IEEE Trans. Geosci. Remote Sensing 57, 6946-6959. https://doi.org/10.1109/TGRS.2019.2909739

Brunt, K.M., Neumann, T.A., Walsh, K.M., Markus, T., 2014. Determination of Local Slope on the Greenland Ice Sheet Using a Multibeam Photon-Counting Lidar in Preparation for the ICESat-2 Mission. IEEE Geosci. Remote Sensing Lett. 11, 935939. https://doi.org/10.1109/LGRS.2013.2282217

Brunt, K.M., Hawley, R.L., Lutz, E.R., Studinger, M., Sonntag, J.G., Hofton, M.A., Andrews, L.C., Neumann, T.A., 2017. Assessment of NASA airborne laser altimetry data using groundbased GPS data near Summit Station, Greenland. The Cryosphere 11, 681-692. https://doi.org/10.5194/tc-11-681-2017

Brunt, Kelly M., Neumann, T.A., Larsen, C.F., 2019a. Assessment of altimetry using ground-based GPS data from the 88S Traverse, Antarctica, in support of ICESat-2. The Cryosphere 13, 579-590. https://doi.org/10.5194/tc-13-5792019

Brunt, K. M., Neumann, T.A., Smith, B.E., 2019b. Assessment of ICESat-2 Ice Sheet Surface Heights, Based on Comparisons Over the Interior of the Antarctic Ice Sheet. Geophys. Res. Lett. 46, 13072-13078. https://doi.org/10.1029/2019GL084886

Brunt, K.M., Smith, B.E., Sutterley, T.C., Kurtz, N.T., Neumann, T.A., 2021. Comparisons of Satellite and Airborne Altimetry With Ground-Based Data From the Interior of the Antarctic Ice Sheet. Geophys Res Lett 48. https://doi.org/10.1029/2020GL090572

Cui, X., Du, W., Xie, H., Sun, B., 2020. The ice flux to the Lambert Glacier and Amery Ice Shelf along the Chinese inland traverse and implications for mass balance of the drainage basins, East Antarctica. Polar Research 39. https://doi.org/10.33265/polar.v39.3582

Ding, M., Xiao, C., Li, Y., Ren, J., Hou, S., Jin, B., Sun, B., 2011. Spatial variability of surface mass balance along a traverse route from Zhongshan station to Dome A, Antarctica. Journal of Glaciology 57, 658-666. https://doi.org/10.3189/002214311797409820

Fricker, H.A., 2005. Assessment of ICESat performance at the salar de Uyuni, Bolivia. Geophys. Res. Lett. 32, L21S06. https://doi.org/10.1029/2005GL023423

Greene, C.A., Gwyther, D.E., Blankenship, D.D., 2017. Antarctic Mapping Tools for Matlab. Computers \& Geosciences 104, 151-157. https://doi.org/10.1016/j.cageo.2016.08.003

Hofton, M.A., Luthcke, S.B., Blair, J.B., 2013. Estimation of ICESat intercampaign elevation biases from comparison of lidar data in East Antarctica: ESTIMATING ICESat ELEVATION
BIASES. Geophys. Res. Lett. 40, 5698-5703. https://doi.org/10.1002/2013GL057652

Kohler, J., Neumann, T.A., Robbins, J.W., Tronstad, S., Melland, G., 2013. ICESat Elevations in Antarctica Along the 2007-09 Norway-USA Traverse: Validation With Ground-Based GPS. IEEE Trans. Geosci. Remote Sensing 51, 1578-1587. https://doi.org/10.1109/TGRS.2012.2207963

Li, B., Zang, N., Ge, H., Shen, Y., 2019. Single-frequency PPP models: analytical and numerical comparison. J Geod 93, 24992514. https://doi.org/10.1007/s00190-019-01311-4

Luthcke, S.B., Thomas, T.C., Pennington, T.A., Rebold, T.W., Nicholas, J.B., Rowlands, D.D., Gardner, A.S., Bae, S., 2021. ICESat-2 Pointing Calibration and Geolocation Performance. Earth Space Sci 8. https://doi.org/10.1029/2020EA001494

Magruder, L., Silverberg, E., Webb, C., Schutz, B., 2005. In situ timing and pointing verification of the ICESat altimeter using a ground-based system. Geophys. Res. Lett. 32, L21S04. https://doi.org/10.1029/2005GL023504

Magruder, L.A., Brunt, K.M., 2018. Performance analysis of airborne photon-counting lidar data in preparation for the ICESat-2 mission. IEEE Transactions on Geoscience and Remote Sensing 56, 2911-2918.

Magruder, L.A., Brunt, K., Neumann, T., Klotz, B., Alonzo, M., 2020a. Passive ground-based optical techniques for monitoring the on-orbit ICESat-2 altimeter geolocation and footprint diameter (preprint). Climatology (Global Change). https://doi.org/10.1002/essoar.10504571.1

Magruder, L.A., Brunt, K.M., Alonzo, M., 2020b. Early ICESat2 on-orbit Geolocation Validation Using Ground-Based Corner Cube Retro-Reflectors. Remote Sensing 12, 3653. https://doi.org/10.3390/rs12213653

Markus, T., Neumann, T., Martino, A., Abdalati, W., Brunt, K., Csatho, B., Farrell, S., Fricker, H., Gardner, A., Harding, D., Jasinski, M., Kwok, R., Magruder, L., Lubin, D., Luthcke, S., Morison, J., Nelson, R., Neuenschwander, A., Palm, S., Popescu, S., Shum, C., Schutz, B.E., Smith, B., Yang, Y., Zwally, J., 2017. The Ice, Cloud, and land Elevation Satellite-2 (ICESat-2): Science requirements, concept, and implementation. Remote Sensing of Environment 190, 260-273. https://doi.org/10.1016/j.rse.2016.12.029

Neumann, T.A., Martino, A.J., Markus, T., Bae, S., Bock, M.R., Brenner, A.C., Brunt, K.M., Cavanaugh, J., Fernandes, S.T., Hancock, D.W., Harbeck, K., Lee, J., Kurtz, N.T., Luers, P.J., Luthcke, S.B., Magruder, L., Pennington, T.A., Ramos-Izquierdo, L., Rebold, T., Skoog, J., Thomas, T.C., 2019. The Ice, Cloud, and Land Elevation Satellite - 2 mission: A global geolocated photon product derived from the Advanced Topographic Laser Altimeter System. Remote Sensing of Environment 233, 111325. https://doi.org/10.1016/j.rse.2019.111325

Schröder, L., Richter, A., Fedorov, D.V., Eberlein, L., Brovkov, E.V., Popov, S.V., Knöfel, C., Horwath, M., Dietrich, R., Matveev, A.Y., Scheinert, M., Lukin, V.V., 2017. Validation of satellite altimetry by kinematic GNSS in central East Antarctica. The Cryosphere 11, 1111-1130. https://doi.org/10.5194/tc-11$1111-2017$ 
Siegfried, M.R., Hawley, R.L., Burkhart, J.F., 2011. HighResolution Ground-Based GPS Measurements Show Intercampaign Bias in ICESat Elevation Data Near Summit, Greenland. IEEE Trans. Geosci. Remote Sensing 49, 3393-3400. https://doi.org/10.1109/TGRS.2011.2127483

Smith, B., Fricker, H.A., Holschuh, N., Gardner, A.S., Adusumilli, S., Brunt, K.M., Csatho, B., Harbeck, K., Huth, A., Neumann, T., Nilsson, J., Siegfried, M.R., 2019. Land ice heightretrieval algorithm for NASA's ICESat-2 photon-counting laser altimeter. Remote Sensing of Environment 233, 111352. https://doi.org/10.1016/j.rse.2019.111352

Zwally, H.J., Schutz, B., Abdalati, W., Abshire, J., Bentley, C., Brenner, A., Bufton, J., Dezio, J., Hancock, D., Harding, D., Herring, T., Minster, B., Quinn, K., Palm, S., Spinhirne, J., Thomas, R., 2002. ICESat's laser measurements of polar ice, atmosphere, ocean, and land. Journal of Geodynamics 34, 405445. https://doi.org/10.1016/S0264-3707(02)00042-X 